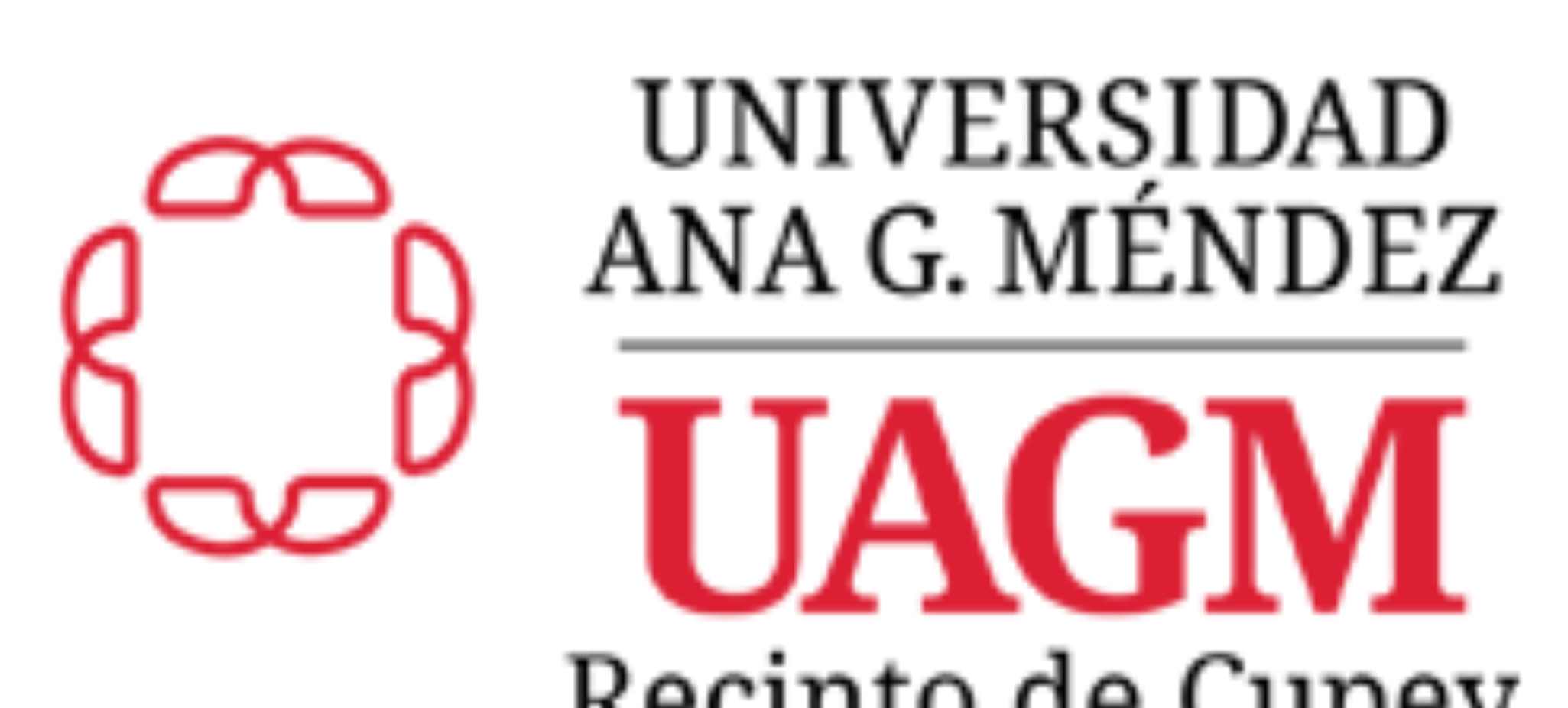

Recinto de Cupey

\title{
Shaping the Scientist of the Future, one Science Demo at a Time
}

\author{
Villa-Del Valle, Kiara N. ${ }^{1}$; Dátiz-Torres, Ana; Dávila-Torres, Nicole; \\ Rivera-Nieves, Alejandra; Morales-Penningston, Nelson F. ${ }^{2}$

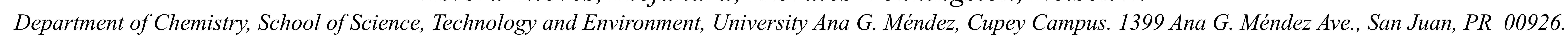
kvilla24@email.uagm.edul, moralesn2@uagm.edu ${ }^{2}$

\section{Mission}

As students we have taken upon ourselves to act as leaders, promoting the importance of Science and more specifically, Chemistry, through demonstrations and activities designed to ignite interest in children and future scientists.

\section{Vision}

Our vision, as ACS members, is to organize and provide opportunities that target children, precollege students, and undergraduates alike to get more involved in the scientific community and its many branches. We promote involvement by organizing demonstrations, special events and activities for schools, community centers, and universities.

\section{Plan}

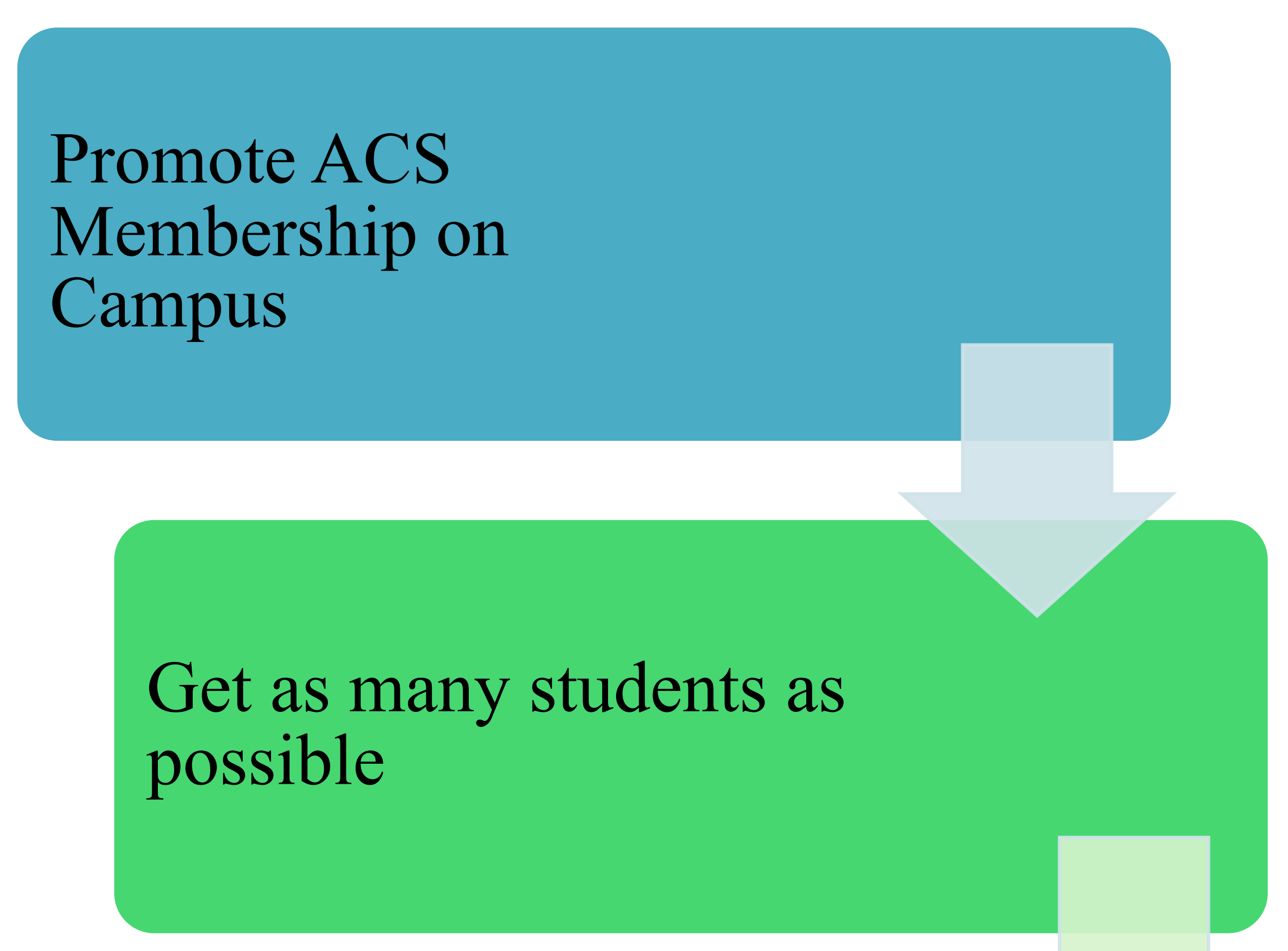

Raise funds for equipment and materials

Visit Schools, Parks, and Events to Promote Chemistry through Demonstrations

\section{Accomplishments}

\section{Membership Increase}

- The ACS UAGM Cupey Campus Student Chapter has a total of 35 members. We aim to increase this number each academic year.

Collaborating with other Academic Chapter

- Each semester we aim to organize at least one activity with other campus associations.

Undergraduate Development

- Assist tutoring for students in Math,

Physics, and Chemistry

- Provide guidance to students for Summer Internships in a wide array of scientific fields

- Provide help with Internship Applications

Member Development

- Fostered teamwork and activities to share with our members

- Senior members collaborated to help younger members organize their schedules

- Promoted the student's interest for Graduate School in Science.

\section{Future Plan}

We aspire to keep growing as a chapter, and to be able to share our passion for chemistry with our audience. We specially want to embolden and reinforce the scientific passions of potential scientists, by mentoring and developing a Science Club at a local school. Additionally, host and be part of new Green Chemistry activities.

Figure 6. Poster y Postres: Presentation

Figure 4. Breast Cancer Awarenes

Figure 5. PIB: Marvelous Metals

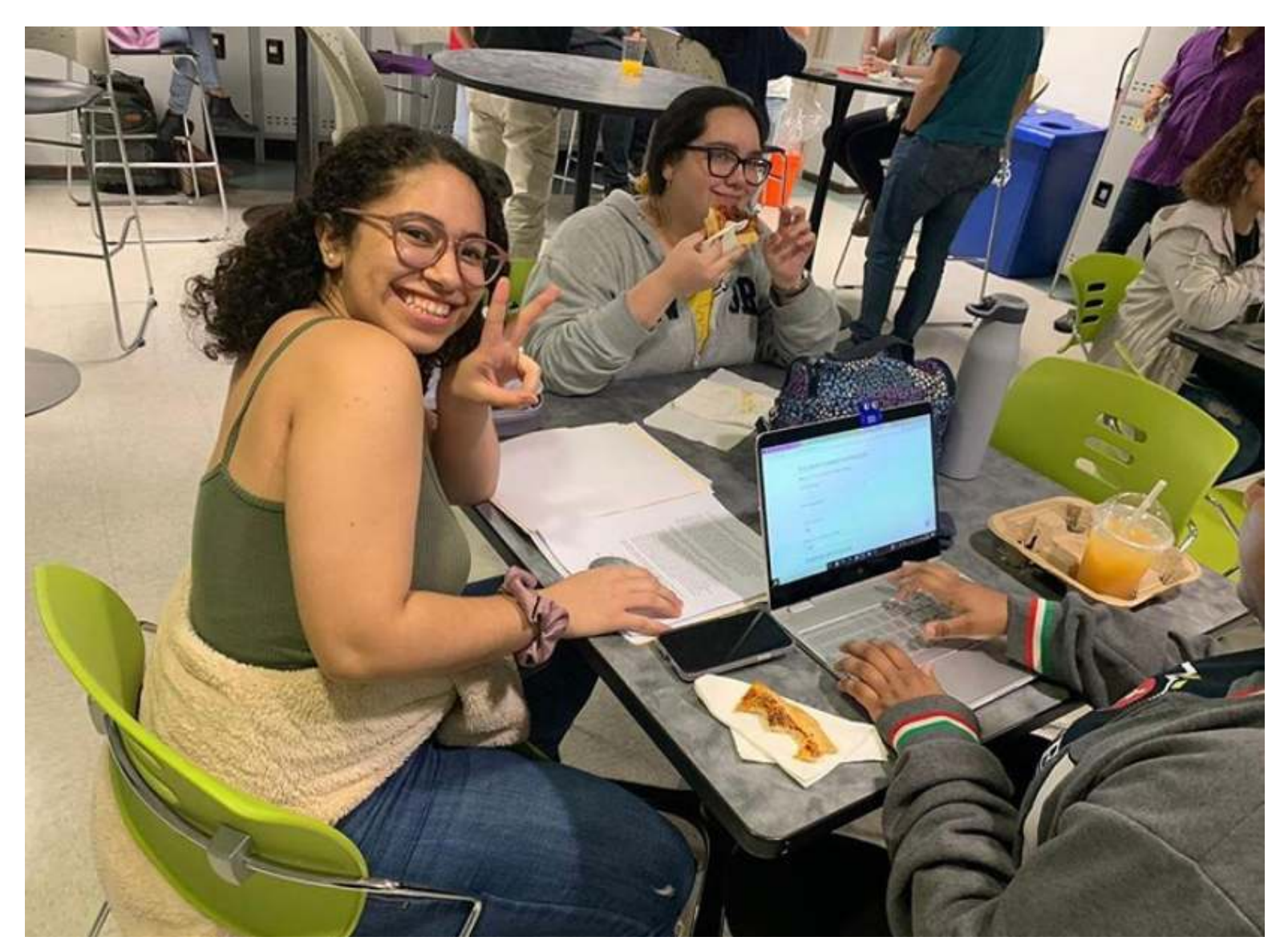

Figure 9. PIB: Future of Food

\section{Track Our Movement}

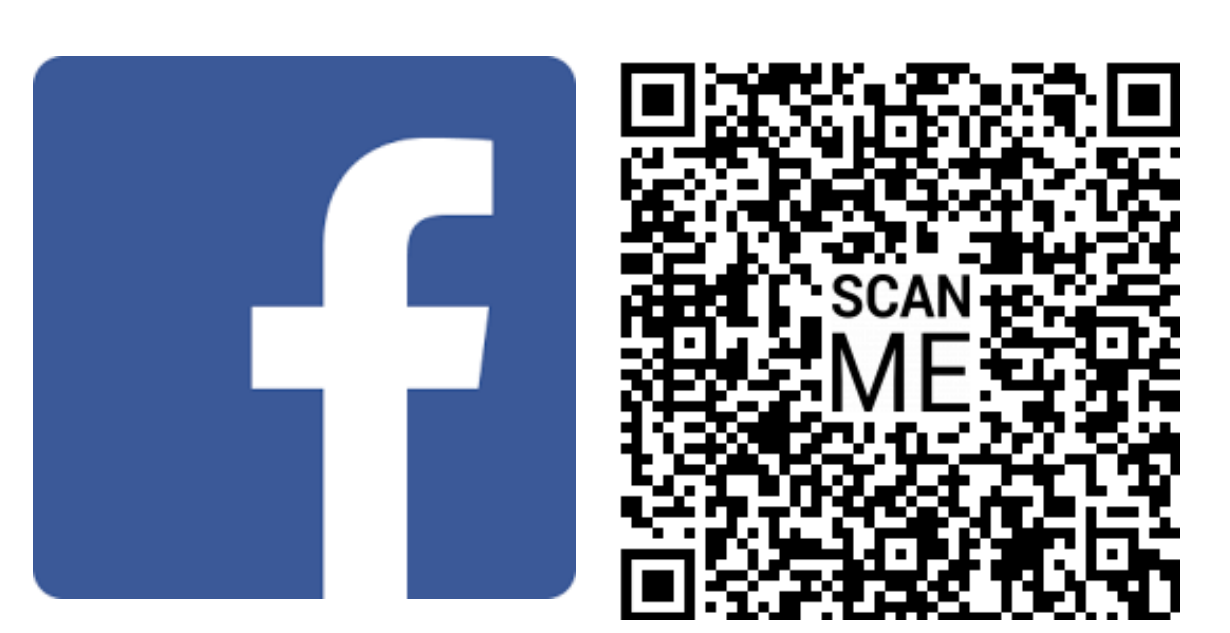

ACS UMET

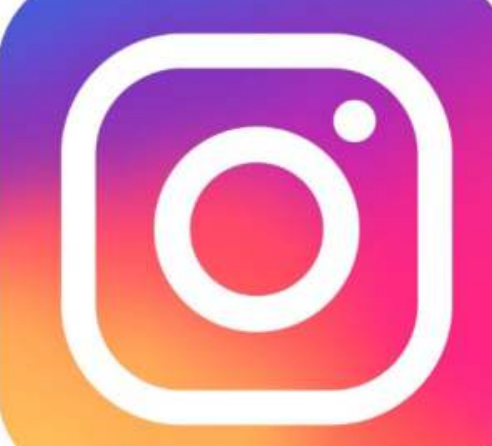

@acs.uagmcupeychapter 